\title{
Effects of ethanol on the kinetics of methyl ethyl
} ketone in man

\author{
Juha Liira, Vesa Riihimäki, Kerstin Engström
}

\begin{abstract}
The kinetics of inhaled methyl ethyl ketone (MEK) at a concentration of $200 \mathrm{ppm}$ for four hours were studied in volunteers after swallowing ethanol at a dose of $0.8 \mathrm{~g} / \mathrm{kg}$. Ethanol was given either before or at the end of the exposure to MEK. The blood concentrations of MEK, 2-butanol, and 2,3-butanediol were monitored during and after the exposure. MEK concentrations in exhaled air and MEK and 2,3-butanediol concentrations in urine were also measured. Ethanol inhibited the primary oxidative metabolism of MEK and caused an increase in the blood concentrations of MEK and 2-butanol after ingestion. Ethanol ingestion, through higher blood MEK concentrations, also increased the elimination of MEK in the urine and exhaled air. Ethanol taken before exposure to MEK reduced the serum concentration of 2,3-butanediol initially but there was an increase about eight hours after the exposure. Urinary excretion of 2,3butanediol followed the same pattern. Prior ingestion of ethanol thus seemed to interfere with the metabolism of 2,3-butanediol during and after exposure to MEK.
\end{abstract}

The inhibitory effects of acute ethanol ingestion on the liver biotransformation activities are well known. ${ }^{12}$ The metabolism of common industrial aromatic solvents such as toluene, m-xylene, and styrene are inhibited by ethanol taken simultaneously..$^{3-6}$ These solvents are effectively extracted by the liver. Absorbed methyl ethyl ketone (MEK) is also extensively metabolised in man but at a clearly lower rate than aromatics. ${ }^{78}$ After oral ${ }^{9}$ and intraperitoneal ${ }^{10}$ administration of MEK the main route of metabolism yielded 3-hydroxy-2-butanone (3H2B) and 2,3-butanediol (2,3-BD) in rats and

\footnotetext{
Turku Regional Institute of Occupational Health, SF-20500 Turku, Finland

J Liira

K Engström

Institute of Occupational Health, SF-00250, Helsinki V Riihimäki
}

guinea pigs; a minor and reversible pathway produces 2-butanol. ${ }^{10}{ }^{10} 2,3-\mathrm{BD}$ and $3 \mathrm{H} 2 \mathrm{~B}$ were found in the urine of subjects exposed to MEK, which supports the idea that the metabolism in man is similar to that in animals. ${ }^{711} \mathrm{MEK}$ is supposedly metabolised by the P450 mediated microsomal mono-oxygenase system ${ }^{12}$ known to be influenced by the intake of ethanol. This experiment was designed to study the metabolic interactions between ethanol and MEK with special emphasis on the kinetics of MEK.

\section{Material and methods}

Five male volunteers with a mean age of 23 years (range 22-24), mean weight of $70 \cdot 2 \mathrm{~kg}$ (range 63-77), and mean height of $180 \mathrm{~cm}$ (range 165-185) were studied. The mean minute ventilation at sedentary exposure was estimated to be about $11 \mathrm{l} / \mathrm{min}$ based on measurements in previous studies involving nearly similar subjects in identical conditions. ${ }^{13}$ The subjects gave their informed consent and the principles of the Declaration of Helsinki (1964) concerning medical studies in man were strictly followed. The study was accepted by the ethical committee of the Institute of Occupational Health. No abnormalities were found during clinical examinations of the volunteers before and after the study.

The exposures to MEK were carried out in a dynamic flow exposure chamber as described in earlier studies. ${ }^{13}$ Analytical grade MEK (MerckSchuchard, Darmstadt, FRG) and $96 \%$ ethyl alcohol (Alko, Finland) mixed with pineapple juice (final concentration about $30 \%$ ) were used. The subjects inhaled MEK for four hours at a target concentration of $200 \mathrm{ppm}$ on three different days with a one week interval between exposures. The exposures were conducted from 0800 to 1200 in the morning and the test subjects had a meal at about 1100 . One exposure involved MEK alone. In the two other exposures ethanol was ingested, either half an hour before the start of the MEK inhalation or half an hour before the end of the exposure. The mean concentration of MEK during the exposures was $203 \pm 3$ (SD) ppm (range 178-227).

Samples of venous blood and expired air were collected during the exposure and over eight hours after the exposure. Venous blood was obtained through a needle inserted into a large forearm vein. 
The exhaled air samples were collected with a two way respirator mouthpiece into polyester laminated four litre aluminium foil bags. A clip was used to prevent nose breathing. Urine samples were obtained every two hours during and every four hours after the exposure, and the subjects were requested to collect all urine voided in separate samples until the next morning.

\section{ANALYSIS OF SAMPLES}

The concentrations of MEK, 2-butanol, and ethanol in whole venous blood were determined using the head space method and capillary gas chromatography (Hewlett-Packard (HP) 5890, capillary column OV$1701,25 \mathrm{~m}$, ID $0.32 \mathrm{~mm}$, phaselayer $0.25 \mu \mathrm{m}$, equipped with a flame ionisation detector). One millilitre of venous blood with $300 \mathrm{mg}$ of $\mathrm{K}_{2} \mathrm{CO}_{3}$ was sealed with a Teflon covered rubber plug in a $20 \mathrm{ml}$ glass serum vial and kept at $80^{\circ} \mathrm{C}$ for 1.5 hours before sampling. The height of the peaks were compared with a calibration curve prepared from known concentrations of MEK, 2-butanol, and ethanol in blood.

The concentration of MEK in exhaled air was analysed by capillary gas chromatography (HP 5890, capillary column OV $101,12.5 \mathrm{~m}$, ID $0.2 \mathrm{~mm}$, phaselayer $0.33 \mu \mathrm{m}$ ). The air samples were drawn through the walls of the aluminium foil bags immediately after the exposure with a $5 \mathrm{ml}$ gas tight syringe and injected through a gas sampling valve into the chromatograph (loop volume $0.5 \mathrm{ml}$ ). Analyses were made at room temperature and the height of the peak was compared with a calibration curve prepared from known concentrations of MEK in bags.

Urine samples $(4 \mathrm{ml}$ ) were sealed in $20 \mathrm{ml}$ glass serum vials, kept at $60^{\circ} \mathrm{C}$ for two hours and the concentrations of MEK analysed by capillary gas chromatography (HP 5890, capillary column OV 101). Standards for comparison were prepared in pooled urine by adding measured amounts of MEK.

The concentrations of 2,3-BD in serum and urine were analysed using a modification of the method of Robinson and Reive. ${ }^{14}$ One millilitre of the sample was mixed with $1 \mathrm{ml}$ of acetone in an ultrasonic bath for five minutes and centrifuged for 20 minutes at $2200 \mathrm{rpm} ; 250 \mu \mathrm{l}$ of the clear supernatant were mixed with an equal amount of n-butyl boronic acid $(5 \mathrm{mg} /$ $\mathrm{ml}$ of acetone); and $1 \mu \mathrm{l}$ of the derivatised sample was injected into a capillary gas chromatograph (HP $5880 \mathrm{~A}$, capillary column SE 54, length $25 \mathrm{~m}$, ID 0.32 $\mathrm{mm}$, equipped with a flame ionisation detector). The 2,3-BD isomers were separated into two peaks in the chromatograph (d- and l-forms, and mesoform).

In calculations these two peaks were summed. The lowest detectable concentration of 2,3-BD was $2 \cdot 2$ $\mu \mathrm{mol} / \mathrm{l}$. The coefficient of variation in the paired samples was $6.4 \%$ at a concentration of $11.1 \mu \mathrm{mol} / 1$ and $1 \cdot 8^{\circ}{ }_{0}$ at a concentration of $111.0 \mu \mathrm{mol} / 1$. Serurf samples were analysed separately, but the urin $\overrightarrow{\hat{c}}$ samples of all five subjects were pooled according to the time of collection.

\section{KINETIC CALCULATIONS}

The pulmonary retention, $\mathrm{R}\left({ }^{\circ}{ }_{0}\right)$, was calculate\& according to the formula $\mathrm{R}=\left(\mathrm{C}_{\mathrm{exp}}-\mathrm{C}_{\mathrm{exh}}\right) / \mathrm{C}_{\mathrm{exp}} \times 100 \mathrm{os}$ where $\mathrm{C}_{\operatorname{cxp}}$ is the inhaled solvent concentration anछ $\mathrm{C}_{\mathrm{cxh}}$ is the concentration in exhaled air samples. The total pulmonary uptake, $\mathrm{U}_{\mathrm{t}}(\mathrm{mmol})$, was calculated using the formula $U_{t}=\left(C_{\text {exp }}-C_{\text {exh }}\right) \times V \times t$, where $\mathbb{f}$ is the minute ventilation $(11 \mathrm{l} / \mathrm{min})$ and $t$ is the exposure time ( $\mathrm{min}$ ).

The apparent clearance, $\mathrm{Cl}_{\text {app }}(\mathrm{l} / \mathrm{min})$, was calculated from the formula $\mathrm{Cl}_{\mathrm{app}}=\mathrm{U}_{\mathrm{t}} / \mathrm{AUC}$, wherE AUC is the area under the blood concentration tims curve $(\mu \mathrm{mol} \times \min / 1)$. AUC was calculated using the trapezoidal rule during the exposure and the follow up period. The AUC for the terminal elimination phase was estimated using the slow phase eliminatio rate constant detected in earlier studies for MEK $\left(\mathrm{k}_{\text {beta }}=0.007 \mathrm{l} / \mathrm{min}\right)^{8}$

\section{Results}

The pulmonary retention of MEK varied between $46.0^{\circ}{ }_{0}$ and $55 \cdot 8^{\circ}{ }_{0}$ in different exposures (table 1). I earlier studies with similar exposures and the same methods of sampling and analysis the pulmonare retention of MEK varied between $41^{\circ}{ }_{0}$ and $53^{\circ}{ }_{0}{ }^{7}{ }^{\circ}$ The measurement of pulmonary retention seemed t艿 be influenced more by variations in the breathing pattern during the collection of samples than potential changes in uptake. The measured pulmonar retentions were used in calculating total pulmonary uptake of MEK (table 1). Although the blood cone centration of MEK was increased by prior intake of. ethanol as shown by the increased AUC for MEK (table 1), no systematic effect on the total pulmonar疋 uptake could be shown.

In the morning blood ethanol concentratio

Table 1 Pulmonary retention and estimated pulmonary uptake of $M E K$ during the exposure, area under the curve ( $A U C)$, and apparent total clearance of $M E K$ in the exposure to $200 \mathrm{ppm}$ for four hours. (Numerical results are means $\pm S D$ of five test subjects)

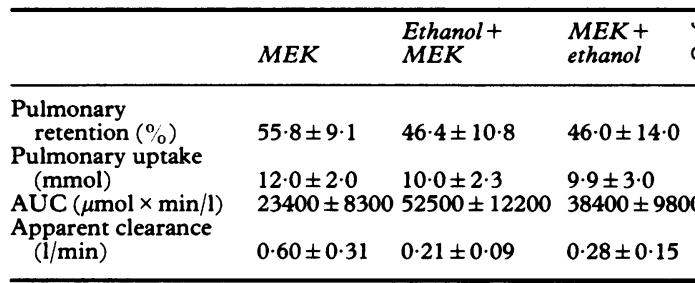

$\mathrm{MEK}=$ Exposure to MEK alone

Ethanol $+\mathrm{MEK}=$ Exposure with preceding intake of ethanol.

$\mathrm{MEK}+$ ethanol $=$ Exposure with intake of ethanol at end exposure. 
Table 2 Blood ethanol concentrations ( $B A C$, mmol/l), means $\pm S D$, in five volunteers of the combined ethanol$M E K$ study. Ethanol $(0.8 \mathrm{~g} / \mathrm{kg})$ was ingested before (0730) or at the end of (1130) exposure to $200 \mathrm{ppm}$ of $M E K$ for four hours

\begin{tabular}{lll}
\hline & \multicolumn{2}{l}{ Ethanol administration } \\
\cline { 2 - 3 } Time & \multicolumn{3}{l}{0730} & 1130 \\
& $B A C$ & $B A C$ \\
\hline 0810 & $15 \cdot 1 \pm 6 \cdot 3$ & \\
0830 & $18 \cdot 6 \pm 5 \cdot 9$ & \\
0900 & $17 \cdot 5 \pm 4 \cdot 5$ & \\
1000 & $15 \cdot 4 \pm 4 \cdot 1$ & \\
1100 & $10 \cdot 0 \pm 2 \cdot 9$ & $5 \cdot 1 \pm 4 \cdot 3$ \\
1200 & $5 \cdot 5 \pm 2 \cdot 8$ & $10 \cdot 0 \pm 1 \cdot 7$ \\
1230 & $3 \cdot 7 \pm 0 \cdot 4$ & $11 \cdot 0 \pm 1 \cdot 0$ \\
1300 & $1 \cdot 0 \pm 0 \cdot 5$ & $10 \cdot 1 \pm 1 \cdot 4$ \\
1400 & & $5 \cdot 9 \pm 2 \cdot 3$ \\
1500 & & $4 \cdot 3 \pm 2 \cdot 4$ \\
1600 & & $2 \cdot 1 \pm 2 \cdot 4$ \\
1700 & & \\
\hline
\end{tabular}

reached its maximum within one hour after the ingestion, whereas at noon the preceding food intake slowed down absorption of ethanol and the peak concentration of ethanol in blood was reached at about 1.5 hours (table 2 ).

Ethanol ingestion increased the blood concentration of MEK considerably in both exposure modes
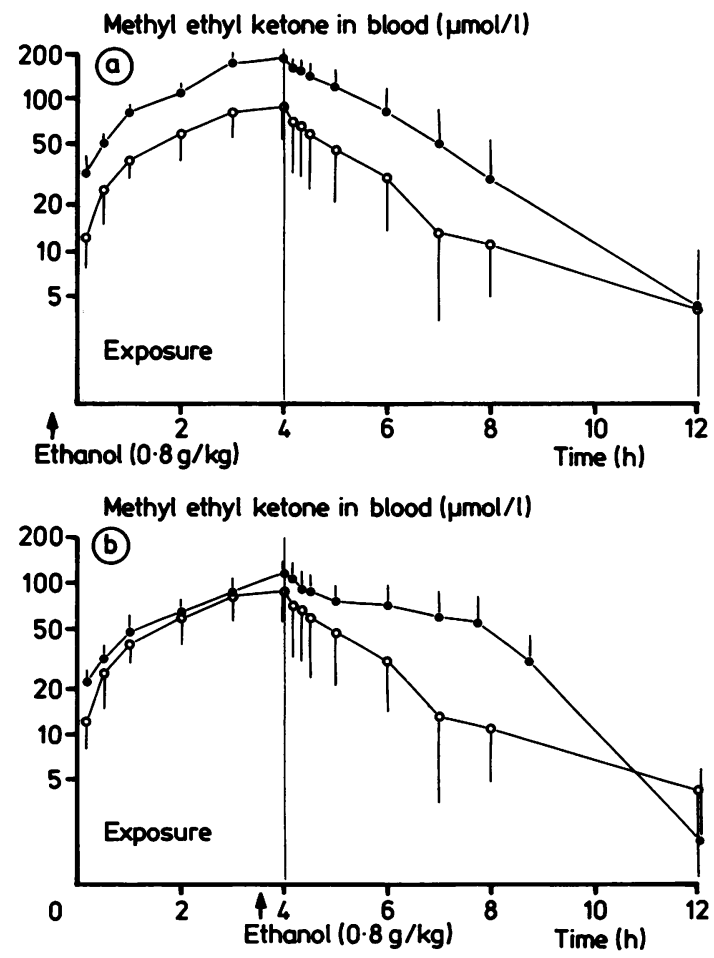

Figure 1 Concentration of methyl ethyl ketone in blood (mean and SD) during and after exposure to 200 ppm of $M E K$ for four hours (open circles) and same exposure with (a) preceding ethanol ingestion $(0.8 \mathrm{~g} / \mathrm{kg})$ (closed circles) and (b) ethanol ingested at end of exposure (closed circles).

\section{2-Butanol in blood ( $\mu \mathrm{mol} / \mathrm{l})$}

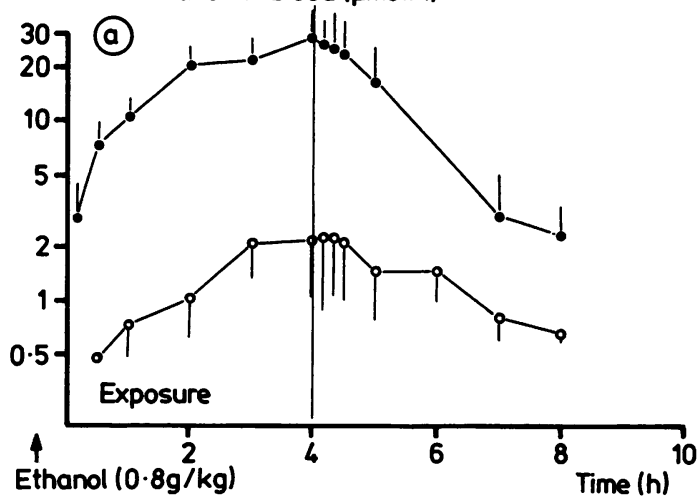

2-Butanol in blood $(\mu \mathrm{mol} / \mathrm{l})$

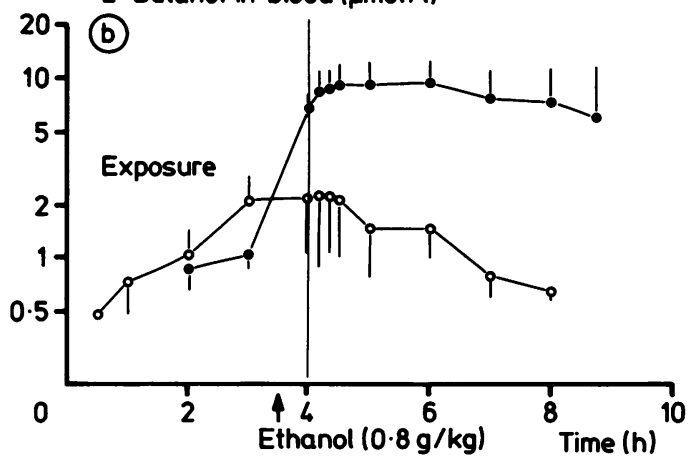

Figure 2 Concentration of 2-butanol in blood (mean and $S D)$ during and after exposure to $200 \mathrm{ppm}$ of $M E K$ for four hours (open circles) and same exposure with (a) preceding ethanol ingestion $(0.8 \mathrm{~g} / \mathrm{kg})$ (closed circles) and (b) ethanol ingested at end of exposure (closed circles).

(fig 1), which suggests an inhibition of the metabolism of MEK by ethanol. When the ethanol intake preceded exposure to MEK, the blood concentration of MEK remained higher throughout the exposure. When ethanol was given at the end of inhalation exposure to MEK a corresponding effect was seen in the elimination phase. The apparent clearance of MEK was also considerably reduced in the presence of ethanol (table 1).

The blood concentration of 2-butanol, a reversible metabolite of MEK, was increased nearly ten times in the presence of ethanol (fig 2), indicating an interference with the metabolism of MEK and eventually of 2-butanol.

The elimination of MEK in expired air increased to about $8 \%$ of the absorbed dose in the presence of ethanol, whereas it was about $3 \%$ in the exposure to MEK alone. Excretion of MEK in the urine doubled in exposures with ethanol ingestion, although the total amount excreted in the urine was less than $1 \%$ of the absorbed dose in all exposures (fig 3, table 3 ). The increased exhalation and urinary excretion 
Methyl ethyl ketone in urine $(\mu \mathrm{mol} / 1)$

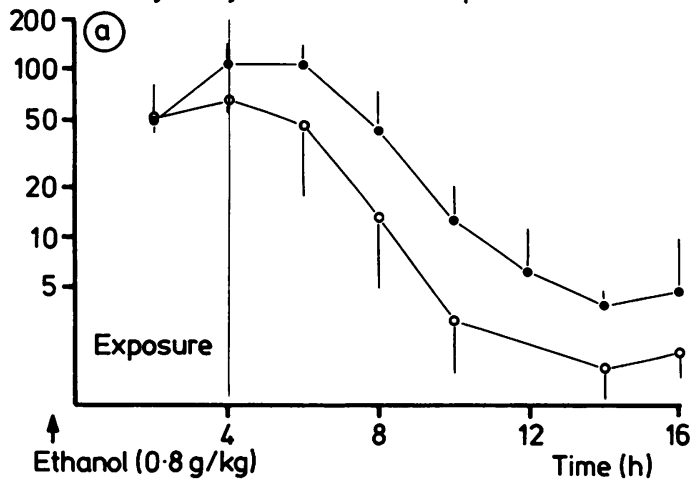

Methyl ethyl ketone in urine $(\mu \mathrm{mol} / \mathrm{l})$

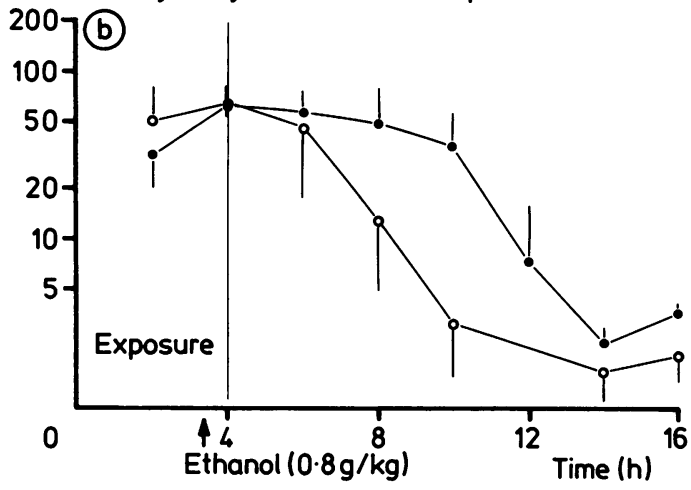

Figure 3 Concentration of methyl ethyl ketone in urine (mean and SD) during and after exposure to 200 ppm of $M E K$ for four hours (open circles) and same exposure with (a) preceding ethanol ingestion $(0.8 \mathrm{~g} / \mathrm{kg})$ (closed circles) and $(b)$ ethanol ingested at end of exposure (closed circles).

reflected the higher blood concentrations of MEK in the presence of ethanol.

The serum concentrations of 2,3-BD were followed up for up to eight hours after the exposure (fig 4). In the exposure to MEK alone the serum concentration of 2,3-BD reached a maximum of

Table 3 Pulmonary excretion of $M E K$ and urinary excretion of $M E K$ (means $\pm S D$ ) and 2,3-BD over $24 \mathrm{~h}$ during and after exposure to 200 ppm of MEK for four hours with or without simultaneous ethanol ingestion (see text in table 1) (2,3-BD excretion was measured from pooled urine samples of five test subjects). (Excretions in percentages from total pulmonary uptake of MEK in parentheses)

\begin{tabular}{|c|c|c|c|}
\hline & $M E K$ & $\begin{array}{l}\text { Ethanol+ } \\
M E K\end{array}$ & $\begin{array}{l}\text { MEK+ } \\
\text { ethanol }\end{array}$ \\
\hline $\begin{array}{l}\text { Pulmonary excretion } \\
\text { (mmol) } \\
\text { Urinary excretion of } \\
\text { MEK ( } \mu \text { mol) } \\
\text { Urinary excretion of }\end{array}$ & $\begin{array}{l}0 \cdot 34 \pm 0 \cdot 14 \\
(2 \cdot 8 \%) \\
26 \cdot 7 \pm 9 \cdot 6 \\
(0 \cdot 2 \%)\end{array}$ & $\begin{array}{l}0 \cdot 82 \pm 0 \cdot 30 \\
(8 \cdot 2 \%) \\
57 \cdot 5 \pm 24 \cdot 9 \\
(0.6 \%)\end{array}$ & $\begin{array}{l}0.75 \pm 0.04 \\
(7 \cdot 6 \%) \\
72 \cdot 3 \pm 45 \cdot 1 \\
(0.7 \%)\end{array}$ \\
\hline $2,3-\mathrm{BD}(\mu \mathrm{mol})$ & $426(3.5 \%)$ & $833(8 \cdot 3 \%)$ & $\begin{array}{l}470 \\
(4 \cdot 7 \%)\end{array}$ \\
\hline
\end{tabular}

Serum 2,3-butanediol ( $\mu \mathrm{mol} / \mathrm{l})$

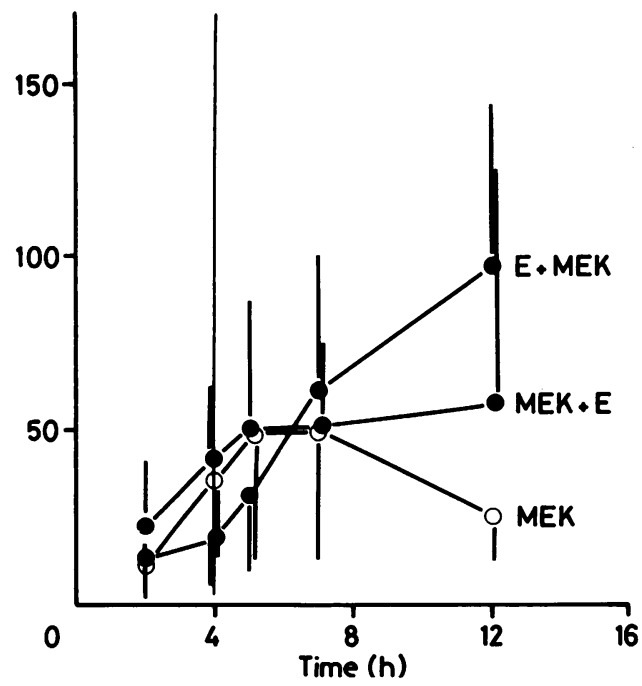

Figure 4 Concentration of 2,3-butanediol in serum (mean and $S D$ ) during and after exposure to $200 \mathrm{ppm}$ of $M E K$ ( $M E K$ ) for four hours (open circles) and same exposure with preceding ethanol ingestion $(E+M E K$, closed circles and with ethanol ingested at end of exposure $(M E K+E$, closed circles).

about $50 \mu \mathrm{mol} / 1$ one to three hours after the end of exposure and then decreased. In the exposure wit preceding ethanol intake the serum concentration of 2,3-BD remained lower than in the exposure to MEI alone during and after the exposure, which might have been caused by the inhibited oxidation of MEK in the presence of ethanol. A reverse phenomenog was seen eight hours after the exposure when the mean serum concentration of 2,3-BD reached maximum of nearly $100 \mu \mathrm{mol} / 1$, possibly indicating $\frac{7}{3}$ further effect of past ethanol on the metabolism of 2,3-BD. In the exposure to MEK with ethanol give later there was a steady concentration of 2,3-BD of about $50 \mu \mathrm{mol} / \mathrm{l}$ over eight hours after the exposure? Unfortunately, the follow up of the serum concentro tions was stopped in the phase when 2,3-BD concen trations were still high in the combined exposure (fig 4).

The urinary excretion of 2,3-BD seemed to follo the pattern of serum concentrations of 2,3-BD an\& the highest excretion was detected after the exposure with previous ethanol ingestion (fig 5). The estimated 24 hour urinary excretion of 2,3-BD wa nearly doubled in the MEK exposure with previous ethanol ingestion, whereas ethanol administration at the end of the exposure had no effect on the urinaro excretion of 2,3-BD (table 3).

\section{Discussion}

Ethanol can be metabolised by the cytoplasmio alcohol dehydrogenase as well as by the microsoma 
Urine 2,3-butanediol excretion ( $\mu \mathrm{mol} / \mathrm{h}$ )

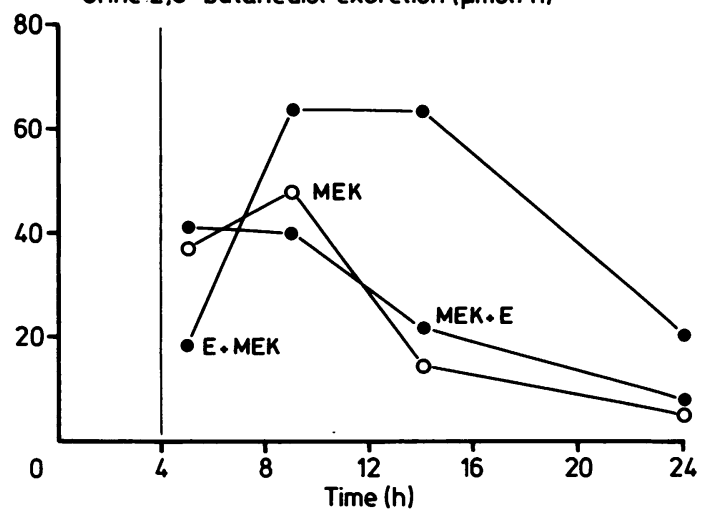

Figure 5 Excretion of 2,3-butanediol in urine after exposure to $200 \mathrm{ppm}$ of $M E K$ ( $M E K$, open circles) for four hours and same exposure with preceding ethanol ingestion ( $E$ $+M E K$, closed circles) and with ethanol ingested at end of exposure ( $M E K+E$, closed circles). Data points were obtained from pooled urine samples from five subjects.

oxidation, ${ }^{15}$ and a specific microsomal ethanol metabolising isoenzyme system has been identified. ${ }^{16}$ In rats large doses of ethanol $(4 \mathrm{~g} / \mathrm{kg})$ inhibited the metabolism of most aromatic and chlorinated hydrocarbons studied. ${ }^{2}$ In in vitro studies competitive and mixed type dose dependent metabolic inhibition of microsomal enzymes were detected when ethanol was given simultaneously. ${ }^{1}$

The oxidation of MEK to 3H2B, a microsomal $\omega-1$ oxidation, is the rate limiting step of MEK metabolism in the rat and guinea pig, ${ }^{910}$ and the reaction seems to proceed only to the oxidative direction. The further reduction of $3 \mathrm{H} 2 \mathrm{~B}$ yields $2,3-\mathrm{BD}$, the known end metabolite of MEK biotransformation. ${ }^{910}$ In our previous studies in man with MEK less than $5 \%$ of the absorbed dose was exhaled as MEK and about $3 \%$ was excreted as 2,3-BD in the urine. ${ }^{78}$ Most of the absorbed MEK is supposedly biotransformed further by routes that have not yet been defined.

In this study ethanol effectively increased the blood concentrations of MEK and decreased the calculated clearance by about a half. The increase in the blood concentration of MEK in the combined exposure is probably caused by the inhibitory effect of ethanol on the microsomal oxidation of MEK. The reduction of MEK to 2-butanol is probably a cytosolic reaction ${ }^{17}$ and 2-butanol is readily oxidised back to MEK, a reaction catalysed both by alcohol dehydrogenase ${ }^{18}$ and the liver microsomal ethanol oxidising system. ${ }^{19}$ Ethanol inhibits the alcohol dehydrogenase dependent 2-butanol oxidation in vitro. ${ }^{20}$

The blood concentration of 2-butanol was low during the exposure to MEK alone but increased 10 times after ethanol ingestion (fig 2). The effect of ethanol could be mediated both by inhibition of
MEK oxidation accompanied by a compensatory activation of MEK reduction to 2-butanol and a further inhibition of 2-butanol oxidation back to MEK. The blood concentration of 2-butanol remained high as long as there were measurable amounts of ethanol in the blood, about six hours after ingestion.

Previous ethanol intake decreased the serum and urine concentrations of 2,3-BD during and shortly after the exposure, which is compatible with a reduced formation of this metabolite in the presence of ethanol. The increased serum and urine concentrations of 2,3-BD many hours after the exposure was unexpected. The metabolism of MEK was somewhat delayed because of the inhibition caused by ethanol, resulting in a higher blood concentration of 2,3-BD in a later phase. The $24 \mathrm{~h}$ urinary excretion of 2,3-BD in the exposure with previous ethanol intake was nearly twice that seen in MEK exposure alone (table 3). Ethanol administered before exposure to MEK might have modified the metabolism of MEK differently shortly after ingestion, as compared with the phase when ethanol was disappearing from the blood.

Perhaps prior ethanol metabolism could interfere in the biodegradation of $3 \mathrm{H} 2 \mathrm{~B}$ or $2,3-\mathrm{BD}$, resulting in an increased serum concentration and urine excretion of 2,3-BD with exposure to MEK. These suggestions are, however, speculative and need to be confirmed.

The skilful technical help of Mr Yrjö Peltonen, Ms Ulla Peltonen, and Ms Eila Korolainen is gratefully acknowledged. We thank the State Alcohol Monopoly for providing ethanol products used in this study.

1 Rubin E, Gang H, Misra P, Lieber C. Inhibition of drug metabolism by acute ethanol intoxication. $A m \mathrm{~J} M e d$ 1970;49:801-6.

2 Sato A, Nakajima T, Koyama Y. Dose-related effects of a single dose of ethanol on the metabolism in rat liver of some aromatic and chlorinated hydrocarbons. Toxicol Appl Pharmacol 1981;60:8-15.

3 Waldron HA, Cherry N, Johnston JD. The effect of ethanol on blood toluene concentration. Int Arch Occup Environ Health 1983;51:365-9.

4 Wallen M, Näslund PH, Byfält Nordqvist $M$. The effect of ethanol on the kinetics of toluene in man. Toxicol Appl Pharmacol 1984;76:414-9.

5 Riihimäki V, Savolainen K, Pfäffi P, Pekati K, Sippel H, Laine A. Metabolic interaction between m-xylene and ethanol. Arch Toxicol 1982;49:253-63.

6 Wilson HK, Robertson SM, Waldron HA, Gompertz D. Effect of alcohol on the kinetics of mandelic acid excretion in volunteers exposed to styrene vapour. $\mathrm{Br} J$ Ind Med 1983;40:75-80.

7 Liira J, Riihimäki V, Pfäffli P. Kinetics of methyl ethyl ketone in man. Absorption, distribution and elimination in inhalation exposure. Int Arch Occup Environ Health 1988;60:195-200.

8 Liira J, Riihimäki V, Pfäffi P. Coexposure of man to m-xylene and methyl ethyl ketone. Scand J Work Environ Health 1988;14:322-7.

9 Dietz FK, Rodriquez-Giaxola M, Traiger GJ, Stella VJ, Himmelstein KJ. Pharmacokinetics of 2-butanol and its metabolites in rat. $J$ Pharmacokinet Biopharm 1981;9:553-76.

10 DiVincenzo GD, Kaplan CJ, Dedinas J. Characterization of the 
metabolites of methyl n-butyl ketone, metyl iso-butyl ketone, and methyl ethyl ketone in guinea pig serum and their clearance. Toxicol Appl Pharmacol 1976;36:511-22.

11 Perbellini L, Brugnone F, Mozzo P, Cocheo V, Caretta D. Methyl ethyl ketone exposure in industrial workers. Uptake and kinetics. Int Arch Occup Environ Health 1984;54:73-81.

12 Traiger GJ, Bruckner JV, Cooke PH. Effect of 2-butanol and 2butanone on rat hepatic ultrastructure and microsomal drug metabolizing enzyme activity. Toxicol Appl Pharmacol 1975;33:132.

13 Riihimäki V, Pfäffli P, Savolainen K, Pekari K. Kinetics of mxylene in man. Scand J Work Environ Health 1979;5:217-31.

14 Robinson DW, Reive DS. A gas chromatographic procedure quantitation of ethylene glycol in postmortem blood. J Anal Toxicol 1981;5:69-72.

15 Crabb DW, Bosron WF, Li TK. Ethanol metabolism. Pharmacol Ther 1987;34:59-73.

16 Coon MJ, Koop DR, Morgan ET. Alcohol oxidation by isozyme 3a of liver microsomal cytochrome P-450. Pharmacol Biochem

Behav 1983;18:177-80.
17 Leibman KC. Reduction of ketones in liver cytosol. Xenobioti站 1971;1:97-104.

18 Merritt AD, Tomkins GM. Reversible oxidation of cychic secondary alcohols by liver alcohol dehydrogenase. $J B$ D Chem 1959;234:2778-82.

19 Krikun G, Cederbaum A. Stereochemical studies on the cyt chrome $\mathrm{P}-\mathbf{4 5 0}$ and hydroxyl radical dependent pathways of 2-butanol oxidation by microsomes from chow-fed, phengbarbital treated, and ethanol-treated rats. Biochemistry 1984;23:5489-94.

20 Dalziel K, Dickinson FM. The kinetics and mechanism of livet alcohol dehydrogenase with primary and secondary alcoholstas substrates. Biochem J 1966;100:34-46.

Accepted 24 July 1989 